\title{
Using Public Service Announcements to Change Behavior: No More Money and Oil Down the Drain ${ }^{1}$
}

Jessica M. Nolan ${ }^{2}$ University of Arkansas, P. Wesley Schultz California State University, San Marcos, Eric S. Knowles University of Arkansas

\begin{abstract}
Radio and television offer promising media for addressing largescale social problems. Unfortunately, very few mass-media messages have utilized social psychological theories of persuasion and influence. This article summarizes 2 studies that evaluated the effectiveness of a state-sponsored public service announcement aimed at reducing improper disposal of used motor oil among doit-yourself oil changers. Study 1 was a field experiment with 120 oil changers in San Diego County. Inertial resistance and low perceived behavioral control were identified as obstacles to proper disposal. In Study 2, we used the disrupt-then-reframe technique to successfully overcome these obstacles and promote proper disposal of used oil. The results underscore the usefulness of empirically validated persuasion techniques in changing behavior via mass media.
\end{abstract}

${ }^{1}$ The authors thank Dave Schroeder and two anonymous reviewers for their comments on an earlier version of this paper. Our appreciation also goes to Dulcinea Contreras and Leezel Nazareno for their help with data collection for Study 1. Portions of this article were presented at the annual meeting of the Society for Personality and Social Psychology, Memphis, TN, January 2007.

${ }^{2}$ Correspondence concerning this article should be addressed to Jessica M. Nolan, who is now at the Department of Psychology, University of Scranton, Scranton, PA 18510. E-mail: nolanj3@scranton.edu

This is the peer reviewed version of the following article: Nolan, J., Schultz, P. W., \& Knowles, E. (2009). Using public service announcements to change behavior: No more money and oil down the drain. Journal of Applied Social Psychology, 39, 1035-1056. http://dx.doi.org/10.1111/j.1559-1816.2009.00471.x. which has been published in final form at Link to Article (http://dx.doi.org/10.1111/j.15591816.2009.00471.x). This article may be used for non-commercial purposes in accordance with Wiley Terms and Conditions for SelfArchiving 
Mass media offer promising communication channels for addressing social problems. They provide a vehicle for reaching hundreds, thousands, even millions of people with a message promoting behavior change. Yet despite the potential reach, these media have been largely ignored by applied social psychologists studying persuasion. While the large-scale nature of many social problems makes mass-media approaches attractive, an effective campaign requires more than creating a message that is understood or liked by the audience (McAlister, Ramirez, Galavotti, \& Gallion, 1989; McGuire, 1989). The message must also motivate the recipient to adopt the marketed behavior.

Unfortunately, many mass-media campaigns lack a theory (or data) for why the desired behavior is or is not occurring, and no theory is used to inform the messaging or persuasive attempt to change a targeted behavior (Atkin \& Freimuth, 1989). Instead, because of a lack of time, resources, or expertise, many mass-media campaigns rely on intuitive theories of human behavior, rather than established social psychological principles of influence (Paisley, 1989).

Examples can be found across the United States, with public service announcements (PSAs) promoting a range of behaviors from energy conservation, water conservation, using public transportation, proper disposal of hazardous waste, and even cleaning up pet excrement. In the late 1990s, the Massachusetts Department of Environmental Protection ran a PSA campaign to increase recycling, encouraging subway riders and radio listeners to "re-make a difference" (East Boston Online, 1997). Likewise, New Yorkers have been asked on various occasions not to "drip New York dry" during water shortages (Department of Environmental Protection, 2002). California residents have been asked repeatedly to "flex their power" and conserve energy, and to "recycle-it's good for the bottle, it's good for the can." Although these PSA campaigns are well intentioned, there is no identifiable behavior change theory at work, and we are skeptical about their efficacy. To our knowledge, none of these campaigns have been evaluated formally.

Research in other areas (e.g., substance abuse) has shown 
that without a theoretical foundation, mass-media campaigns are often ineffective (Rice \& Atkin, 1989). For example, Fishbein, Hall-Jamieson, Zimmer, von Haeften, and Nabi (2002) evaluated the effectiveness of 30 different anti-drug PSAs and found that 16 were more effective than a control group, but 6 actually had a negative effect, increasing participants' intention to use drugs. Similar results have been found for anti-smoking PSAs (Farrelly, Niederdeppe, \& Yarsevich, 2003). Designers working with the Texas Tobacco Prevention Initiative used focus-group conversations to come up with their "Tobacco is foul" campaign, yet evaluations showed that the campaign was generally ineffectual. Indeed, areas of the state exposed only to the mass-media portion of this campaign failed to reduce tobacco use among young people beyond that of a control group (University of TexasHouston, 2001).

These null effects are not uncommon for intuitively derived anti-smoking campaigns and illustrate that focus groups are not a substitute for empirically validated persuasion techniques (Murray, Prokhorov, \& Harty, 1994). Still other mass-media campaigns have found little or no effect on other behaviors, such as healthy eating (e.g., Galst, 1980; Gorn \& Goldberg, 1982) and safe driving (Whittam, Dwyer, Simpson, \& Leeming, 2006).

This is not to say that the mass media are not an appropriate channel for social marketing. In general, mass-media campaigns have been successful when they are created with a theoretical foundation and employ empirically validated persuasion techniques (Bator \& Cialdini, 2000). PSA campaigns that use empirically derived messages have successfully increased recycling (Cialdini et al., 2006), reduced the risk of coronary heart disease (Flora, Maccoby, \& Farquhar, 1989), and changed attitudes toward speeding (Stead, Tagg, MacKintosh, \& Eadie, 2005).

To be successful, PSA campaigns need evidence for why the behavior is or is not occurring, as well as a theory of how to change the targeted behavior. This theory can be broad, as in the case of the psychology of social influence, but should in all cases be empirically supported. In the present study, we 
evaluate an existing mass-media campaign targeting the improper disposal of used motor oil, probe the underlying causes of the behavior, and offer an alternative message designed to address and overcome the obstacles deterring proper disposal. 


\section{Overview}

The improper disposal of used motor oil from vehicles has been high- lighted by numerous environmental organizations as a serious environmental problem. According to a commissioned report by the Public Research Institute at San Francisco State University (Browning \& Shafer, 2002), in California alone, at least 1.6 million gallons of used motor oil end up being poured down storm drains, on the ground, thrown in the trash, or otherwise disposed of in a way that threatens public health and the environment. Used motor oil that is not disposed of properly can contaminate soil and ground- water. Used motor oil contains heavy metals, such as lead, and heavy poly- cyclic aromatic hydrocarbons that are thought to be carcinogenic (Irwin, VanMouwerik, Stevens, Seese, \& Basham, 1998; Vazquez-Duhalt, 1989). The latter present the greatest risk to human, animal, and ecosystem health, with documented negative effects on plant growth and amphibian reproduction. Used motor oil is also the leading source of oil pollution in the waterways of California and across the United States (California Integrated Waste Management Board, 2002).

Clearly, the negative effects of used motor oil in the environment warrant an assertive effort to curb improper disposal. In Study 1, we evaluate existing PSA messages sponsored by the California Integrated Waste Management Board (CIWMB) and investigate the factors that might be related to improper disposal. In Study 2, we selected a behavior change strategy that would address the underlying cause of improper disposal identified in Study 1. We then compared our empirically derived message to the existing state-sponsored PSA. 


\section{Study 1}

As part of a larger outreach campaign, the CIWMB funded a series of radio PSAs to encourage proper disposal of used oil and filters. In analyzing the messages, it seems that the creators were using a knowledge-deficit model of behavior change (cf. Schultz, 2002). Each state-sponsored PSA began with a dialogue between a male character who had previously dumped used motor oil and a scolding family member who had put the oil in an unusual place (e.g., a bathtub). The dialogue of the state-sponsored PSA conveyed to the listener that dumping oil can have harmful effects: "The oil would sink into the ground and could eventually end up in our water supply" (i.e., impact information). Next, a radio announcer's voice came on to implore listeners to call a certain phone number the next time they changed their oil (i.e., action information). The PSA ended by telling listeners that " $50 \%$ of oil sold is never collected" (i.e., descriptive normative information).

The knowledge-deficit model assumes that people fail to perform a given prosocial behavior because they lack information (either action or impact). For example, the statesponsored PSAs under scrutiny in this study presumed that doit-yourself oil changers (DIYers) were unaware of the harmful consequences of dumping oil. However, a report by Browning and Shafer (2002) found no differences on a measure of perceived harmfulness between DIYers who disposed of oil properly versus those who did not. Most of the DIYers surveyed understood that there were harmful consequences associated with improper disposal.

Furthermore, the scenario depicted in the state-sponsored message is conflicted. On the one hand, the message says that disposal of oil down the drain is harmful; on the other hand, the scolding character is essentially disposing of the motor oil filter improperly (e.g., in a bathtub). This contra- diction may have undermined the goal of communicating danger associated with improper disposal. A better choice would have been for the scolding character to model the proper disposal behavior.

The state-sponsored PSA also misused the power of social 
proof. By implying that a majority of people have engaged in improper disposal (i.e., " $50 \%$ of oil sold is never collected") the present message may have actually encouraged this undesirable behavior. Previous research has shown that descriptive normative information can influence behavior, irrespective of valence (Schultz, Nolan, Cialdini, Goldstein, \& Griskevicius, 2007). That is, people change their behavior in the direction of the norm, whether or not the norm is prosocial. The gist of the state-sponsored message could be summarized as "We disapprove of dumping used oil, but most people do it anyway." This type of conflicting message pits norms of approval (i.e., injunctive norms) against norms of prevalence (i.e., descriptive norms) and has been proscribed explicitly in the literature (e.g., Bator \& Cialdini, 2000; Cialdini et al., 2006).

In Study 1, we conducted a field test of the state-sponsored PSA messages with a sample of DIYers in California. The goal of this study is to provide an initial evaluation of the PSA messages under relatively controlled conditions. We also explored the factors that might be related to improper disposal to aid us in developing an alternative message.

\section{Method}

\section{Participants and Procedure}

Participants were 120 customers ( 107 male, 8 female, 5 did not indicate their gender) who were recruited from several Kragen Auto Parts stores in San Diego, California. A sample of 120 was selected in order to provide sufficient power to detect a medium effect in a one-way ANOVA with three groups (40 participants per group).

The researcher told potential participants that she was a student from California State University-San Marcos working to develop new messages about oil recycling. Only customers who reported changing their own oil (DIYers) were selected to participate in the study. In an attempt to reduce social desirability bias, participants were not asked to provide any identifying information during the study. In addition, the researcher told participants "We appreciate your honesty and 
assure you that your answers will be kept strictly confidential." Participants' mean age was 36.1 years $(S D=14.2)$. The ethnic background of most participants was White $(60 \%)$ or Hispanic $(24 \%)$. The majority of participants $(91 \%)$ were male.

Participants were randomly assigned to one of three experimental conditions: full PSA, partial PSA, or control PSA. In the full PSA condition, participants heard two of the 60-s state-sponsored PSAs in their original form, as aired by Los Angeles County. Participants in the partial PSA group also heard the state-sponsored PSAs; however, in this condition, the messages were edited to exclude the low descriptive normative information (i.e., " $50 \%$ of motor oil sold is never collected") at the end of the message. In both of the treatment conditions, the two messages were strung together, back to back, and lasted a total of approximately $120 \mathrm{~s}$. In the control condition, participants heard a series of four unrelated PSAs promoting road sharing and safe driving that also lasted approximately $120 \mathrm{~s}$.

All participants were seated alone at a table in front of the auto parts store and were asked to listen to the PSAs with headphones. After listening to the messages, participants completed a 25-item questionnaire. The main dependent variables in this study were the participants' behavioral intentions related to proper disposal of oil and oil filers. Intention to dispose of used oil properly was measured with three items (e.g., "The next time you need to dispose of used motor oil, how likely is it that you would take it to a collection center?"). Intention to dispose of used oil filters was measured with two items (i.e., "The next time you need to dispose of a used motor oil filter, how likely is it that you would take it to a collection center?" and "The next time you need to dispose of a used motor oil filter, how likely is it that you would throw it in the trash?"). Responses were rated on a 5-point scale ranging from 1 (very unlikely) to 5 (very likely).

Because we are interested in the factors underlying improper disposal, we also asked participants how many times they had changed their oil in the past year, and how they disposed of the used oil on each occasion. We coded respondents as good citizens if they reported always disposing of oil properly, and as 
dumpers if they disposed of used oil improperly on one or more occasions. We also measured the following psychological constructs that have been shown to be related to environmental behavior: perceived behavioral control (Chu \& Chiu, 2003; Laudenslager, Holt, \& Lofgren, 2004), subjective norm (Ewing, 2001; Kantola, Syme, \& Campbell, 1984), ascription of responsibility (Van Liere \& Dunlap, 1978), personal involvement (Gregory \& Di Leo, 2003), descriptive norm (Hopper \& McCarl Nielsen, 1991), and injunctive normative beliefs (Bratt, 1999).

Perceived behavioral control (PBC) refers to the extent to which a person perceives that the target behavior is under his or her control and was measured with one item: "It is mostly up to me whether or not the used motor oil from my car gets disposed of at a designated collection center." Subjective norm refers to the extent to which a person believes that important others want him or her to perform the target behavior and was measured with one item: "Most people who are important to me think I should dispose of used motor oil at a designated collection center." Ascription of responsibility refers to how much personal responsibility an individual accepts for performing the target behavior and was measured with one item: "I should NOT be held responsible for taking used motor oil to a collection center." Personal involvement refers to the extent to which a person spends time thinking about the target behavior and sees himself or herself as knowledgeable. Personal involvement was measured with four items (e.g., "How knowledgeable are you about used motor oil disposal?"). Descriptive norm refers to a belief about the percentage of other people who engage in the target behavior. Finally, injunctive normative beliefs are beliefs about the extent to which others approve or disapprove of the target behavior.

Participants completed the questionnaire. They were then debriefed, thanked for their time, and given a $\$ 5$ gift card for the automotive store. 


\section{Results and Discussion}

The average respondent reported changing their oil 6.56 times in the past year. The majority of respondents (87\%) were good citizens who reported that they always disposed of their used motor oil properly. Out of 120 respondents, $5 \%$ reported that in the past year they had poured used motor oil on the ground, and $8 \%$ said that they had thrown used oil in the trash, for a total of 11 respondents who were categorized as dumpers. It should be noted that this is probably an underestimate of the true percentage of dumpers in the population (see Schultz, 2006).

To test for differences in intentions to dispose of used oil across the experimental groups, we conducted a one-way ANOVA, $F(2,117)=0.85, n s$. Participants in the full $(M=$ $4.73, S D=0.56)$ and partial PSA $(M=4.59, S D=0.96)$ conditions expressed no greater intention to dispose of used oil properly than those in the control group $(M=4.79, S D=0.52)$. Given that the control group nearly hit the ceiling with a mean of 4.75 on the 5-point scale, it would have been difficult to detect improvements caused by the PSAs. However, the means in the full and partial PSA conditions were actually lower than those of the control group, suggesting that the state- sponsored PSA messages did not have the intended effect of increasing DIYers' intention to dispose of used oil properly in the future. We found similar results for intention to dispose of used oil filters properly, $F(2,117)=1.67, n s$. Participants in the full $(M=4.26, S D=1.30)$ and partial PSA $(M=4.26, S D=1.24)$ conditions did not express significantly greater intentions to dispose of used oil filters properly than those in the control group ( $M=3.80, S D=1.38)$.

Not surprisingly, good citizens expressed significantly greater intentions to dispose of used oil $(M=4.82, S D=0.45)$ and used oil filters $(M=4.25, S D=1.19)$ properly, as compared to dumpers (used oil, $M=3.58, S D=1.49$; used oil filters, $M=2.68, S D=1.69)$, in both cases, $t(118)>4.00, p<$ .001 . Furthermore, when we looked at the behavioral intentions of dumpers only, we found that their intentions to 
dispose of oil properly were the same whether they heard one of the state-sponsored PSAs $(M=3.59, S D=1.69 ; N=8)$ or the control PSA $(M=3.89, S D=0.39 ; N=3)$. Likewise, dumpers' intentions to properly dispose of used oil filters seemed to be unaffected by hearing either version of the statesponsored message. We did not run formal statistical tests on these means because of the low sample size in the control PSA group.

To investigate the factors underlying the tendency to dispose of used oil improperly, we conducted an internal analysis comparing dumpers $(N=11)$ and good citizens $(N=109)$ on measures of $\mathrm{PBC}$, subjective norm, ascription of responsibility, personal involvement, and descriptive and injunctive normative beliefs. Our results show that dumpers scored significantly lower on the measure of ascription of responsibility, $t(117)=$ $3.94, p<.001$; and marginally lower on the measure of PBC, $t(118)=1.60, p=.11$, as compared to good citizens. Table 1 presents means and standard deviations. The results of this internal analysis were used to inform the design of our alternative message in Study 2.

\begin{tabular}{|l|c|c|c|c|}
\hline $\begin{array}{l}\text { Table 1 Means for Selected } \\
\text { Constructs by Oil Disposal } \\
\text { Status }\end{array}$ & \multicolumn{2}{|c|}{ Dumpers } & \multicolumn{2}{c|}{ Good citizens } \\
\hline & $M$ & $S D$ & $M$ & $S D$ \\
\hline Perceived behavioral control & 4.09 & 1.58 & 4.63 & 1.02 \\
\hline Subjective norm & 3.91 & 1.30 & 4.40 & 1.12 \\
\hline Ascription of responsibility & 2.18 & 1.47 & 4.12 & 1.57 \\
\hline Personal involvement & 2.14 & 0.69 & 2.73 & 1.19 \\
\hline Descriptive normative beliefs & 2.91 & 0.62 & 2.96 & 0.73 \\
\hline Injunctive normative beliefs & 4.09 & 0.74 & 3.77 & 0.92 \\
\hline
\end{tabular}

Note. . Dumpers $=$ participants who reported disposing of oil illegally on at least one occasion. 


\section{Study 2}

Study 1 showed that good citizens (i.e., the DIYers who had always disposed of used oil properly in the past) were significantly more likely than dumpers (i.e., those who had improperly disposed of oil even once) to express an intention to dispose of oil properly and to ascribe responsibility for proper disposal to themselves. Good citizens also scored higher on an item measuring PBC, as compared to dumpers. We surmised that those who previously dumped were deterred in part by the potential inconvenience of disposing of the oil and filters, as reflected in their low PBC scores. This initial finding is echoed in the results of a survey in two California counties where residents indicated that inconvenience was a major barrier to disposing of used oil properly (Schultz, 2006). Thus, one of the changes we made to the state- sponsored message was to emphasize that disposing of used motor oil is convenient.

Beyond low PBC, the null results of Study 1 suggest that DIYers also had some level of inertial resistance to the statesponsored message. Inertia may be the result of not being able to change, not knowing how or what to change, or simply not wanting to change (Brown, 2001; Prochaska \& Prochaska, 1999). If it were only a question of knowing how or why to change, then the phone number and impact information in the state-sponsored PSA would have been sufficient to promote proper disposal. In the case of motor oil disposal, the latter option seems most likely (i.e., dumpers lacked the motivation to change). Indeed, in other studies of used oil disposal, lack of motivation was cited by respondents as a barrier to disposing of used oil at a collection center (Schultz, 2006). Our alternative PSA message was designed to reduce inertial resistance and motivate proper disposal simultaneously by addressing the identified obstacle of perceived inconvenience.

\section{Disrupt-Then-Reframe Technique}

Knowles and Riner (2007) suggested that where inertial resistance is strong, it is first necessary to reduce resistance to the persuasion attempt using Omega change strategies. Omega strategies work by removing or dis- engaging resistance to 
change (Knowles \& Linn, 2004). We chose to use the disruptthen-reframe (DTR) technique because it has been used effectively to deal with inertial resistance in previous research (Davis \& Knowles, 1999). The DTR technique uses a small disruption, such as a syntactical violation or non sequitur, to create confusion. Immediately following the disruption, the persuasive message or phrase (i.e., the reframe) is presented.

The DTR technique has its theoretical foundation in Ericksonian (Erickson, 1964) confusion techniques and action identification theory (Vallacher \& Wegner, 1985). In both cases, the addition of a confusing element is predicted to lead to increased susceptibility to social influence. Subsequent research exploring the mechanisms underlying the effectiveness of the DTR technique confirmed that the DTR technique does, in fact, decrease resistance and also makes listeners more vulnerable to other persuasive components contained in the message, particularly the reframe (Fennis, Das, \& Pruyn, 2004).

Davis and Knowles (1999) tested the DTR technique by asking people if they wanted to buy notecards. In the DTR condition, participants were asked "Would you like to buy some notecards? They're 300 pennies.... That's \$3. It's a bargain." They found that $65 \%$ of people complied in the DTR condition, as compared to only $35 \%$ who were simply told the price (i.e., "They're \$3.") or the price and the reframe without the disruption ("They're \$3. It's a bargain."). The disruption in this case was stating the price of the notecards in terms of pennies, instead of the typical dollar amount, and the reframe was "It's a bargain."

The Omega message that we designed was modeled after the original study by Davis and Knowles (1999). This Omega PSA message incorporated aspects of the original state-sponsored message, but also differed in several important ways: (a) we eliminated the contradiction of having the scolding character disposing of the oil filter improperly, and instead emphasized the potential harm of improper disposal; (b) the Omega PSA was not written in dialogue form; (c) the Omega PSA emphasized the convenience of proper disposal; and (d) the Omega PSA contained a DTR component at the end ("Typically, there will be a collection center in less than 47,520 
inches from your home- -that's $3 / 4$ of a mile. It's convenient!").

Thus far, the DTR technique has been used only in face-toface commu- nication (Davis \& Knowles, 1999; Fennis et al., 2004; Kardes, Fennis, Hirt, Tormala, \& Bullington, 2007). However, we hypothesized that it could also be effectively implemented in a mass-media format.

The primary purpose of Study 2 is to compare the empirically based Omega PSA against the existing statesponsored PSA. We predict that the state-sponsored PSA will be ineffective or even counterproductive, while the Omega PSA will effectively promote proper disposal of used motor oil. Specifically, we predict that the Omega PSA will result in greater intentions to properly dispose of used oil filters, as compared to both the control and state-sponsored PSAs, which will not differ from one another.

\section{Method}

\section{Participants}

Study participants were 106 Introductory Psychology students (35 male, 69 female, 2 did not indicate their gender).

Participants' mean age was 20.6 years $(S D=2.8)$, and the majority of participants $(88 \%)$ were White. Among the participants, $9 \%$ said that they changed their oil themselves, and $14 \%$ said they had it changed by a friend or family member. The remainder had it changed professionally. Out of those who reported some involvement in their last oil change, $46 \%$ disposed of the oil properly, $35 \%$ disposed of the oil improperly, and $19 \%$ of the reports did not specify the ultimate fate of the oil (e.g., "gave it to my father"). Note that these participants had no prior exposure to the state-sponsored PSA, which aired only on California stations. 


\section{Materials and Procedure}

In this study, participants read (rather than listened to) a PSA message and completed a survey online. The message was presented in a paced fashion, with one to two sentences per page. Participants were randomly assigned to one of three conditions: state-sponsored PSA, Omega PSA, or control PSA. Both the state-sponsored PSA and the Omega PSA messages targeted proper disposal of oil filters. The control message was formatted like the state-sponsored PSA, but was changed to be about littering, rather than motor oil. The full text of all of the messages is presented in Appendixes A, B, and C.

After reading the message, participants completed a questionnaire. The main dependent measure was "Now, imagine that you found a used oil filter on the ground, clearly leaking oil. What would you do?" Response options were "leave it on the ground," "put it in the trash," "take it to a collection center," and "other." Respondents who chose "other" were asked to write in the specific other action they would take (only 1 person selected this option). Following Study 1, we also measured behavioral intentions related to disposal of used oil filters (e.g., "The next time you need to dispose of a used oil filter, how likely is it that you would take it to a collection center?") and used motor oil (e.g., "The next time you need to dispose of used oil, how likely is it that you would dispose of it in an empty lot?'). To avoid the potential ceiling effects noted in Study 1, the 5-point response scale for behavioral intentions was replaced with a 7-point scale ranging from 1 (strongly disagree) to 7 (strongly agree).

Because the state-sponsored message attempted to make salient the harmful effects of improper disposal of used oil, we chose to measure participants' perceptions that improper disposal is harmful and has adverse consequences. Perceived harmfulness was measured with three items (Cronbach's $\alpha=$ .80). A sample item is "How harmful do you think it is for someone to throw a used oil filter in the trash?". Responses were rated on a 5-point scale ranging from 1 (not harmful at all ) to 5 (very harmful). Awareness of consequences was measured 
with four items; however, the Cronbach's alpha for the aggregate scale was not reliable $(\alpha=.54)$. As an alternative, we chose to examine the single item in the scale related to used oil filters: "If someone put a used oil filter in the trash, the oil could sink into the ground at the landfill and end up in our water supply." Responses were rated on a 4-point scale ranging from 1 (definitely no) to 4 (definitely yes).

Finally, to ensure that any observed differences between the messages were not a result of how much they were liked, we had participants evaluate the messages using a 13-item scale adapted from Fishbein et al. (2002). The scale included items related to how much the message captured participants' attention, as well as items that asked participants how much they liked the message and if they found the message convincing. Responses were rated on a 4-point scale ranging from 1 (definitely no) to 4 (definitely yes). We also included a procedural check to ensure that students attended to the messages.

\section{Results and Discussion}

Analysis of the procedural check shows that $83 \%$ of participants attended to the messages well enough to remember the phone number provided at the end of the message. The reported analyses are for all participants; however, analyses on only those who answered the procedural check correctly produced virtually identical results.

\section{Message Evaluation}

Overall, participants rated the messages favorably. On a 4point scale, the mean response across the 13 items evaluating the ad $(M=2.80)$ is significantly greater than the scale midpoint of $2.50, t(105)=6.90, p<.001$. A one-way ANOVA shows that all three messages were evaluated as equal, $F(2$, $103)=1.08, n s$. When we look at the means for the individual items, we see that there were no significant differences across 
conditions in terms of how much participants liked the messages, $F(2,61)=0.15, n s$; how convincing they found the messages, $F(2,61)=0.67, n s$; or how much the messages captured their attention, $F(2,61)=0.19$, ns.

\section{Behavioral Intentions}

A forced-choice question asked participants what they would do if they found a used oil filter on the ground, leaking oil. A chi-square test on the answers shows significant differences among the groups, $\chi^{2}(6, N=104)=26.82, p<$ .001 . In the Omega group, $53 \%$ of participants said they would take the found filter to a collection center, compared to only $23 \%$ of those who heard the state-sponsored message, and 3\% in the control condition (see Table 2).

Participants' behavioral intentions for disposing of used oil filters properly also differ across conditions, $F(2,103)=3.46, p$ $<.05$. Planned compari- sons show that those who heard the Omega message expressed significantly greater intention $(p \mathrm{~s}<$ $.05)$ to properly dispose of used oil filters $(M=4.15, S D=$ $1.47)$, as compared to the state-sponsored PSA $(M=3.43, S D=$ $3.34)$, and control PSA $(M=3.34, S D=1.52)$ conditions, which did not differ significantly from each other. The pattern of means for intention to dispose of used oil was in the predicted direction, with the Omega group expressing the greatest intention to properly dispose of oil $(M=5.31 S D=$ $0.86)$, as compared to the state-sponsored PSA $(M=4.87 S D=$ $1.14)$ and control PSA groups $(M=5.10, S D=1.06)$. However, these differences were not significant, $F(2,103)=1.72, p=.18$. 
Table 2 Frequency of Responses to Forced-Choice Question Asking Preferred Method of Disposal Across PSA Conditions

\begin{tabular}{|l|c|c|c|}
\hline Method of disposal & $\begin{array}{c}\text { State-sponsored } \\
\text { PSA }\end{array}$ & $\begin{array}{c}\text { Omega } \\
\text { PSA }\end{array}$ & $\begin{array}{c}\text { Control } \\
\text { PSA }\end{array}$ \\
\hline Leave on ground & 14 & 10 & 12 \\
\hline Put in trash & 17 & 6 & 17 \\
\hline Take to collection center & 7 & 19 & 1 \\
\hline Other $^{\mathrm{a}}$ & 0 & 1 & 0 \\
\hline Total & 38 & 36 & 30 \\
\hline
\end{tabular}

Note. Preferred method of disposal indicates method participants would use if they found a used oil filter on the ground. PSA = public service

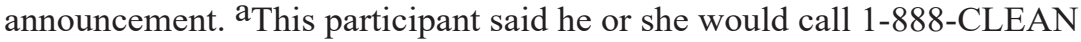
AR.

\section{Perceived Harmfulness and Awareness of Consequences}

We conducted two separate one-way ANOVAs, which show that there were marginally significant differences across the three conditions on the measures of awareness of consequences, $F(2,102)=2.8, p<.07$; and perceived harmfulness, $F(2,103)=2.80, p=.07$. The Omega PSA group reported greater awareness of consequences $(M=3.27$ on a 4-point scale), as compared to the state-sponsored PSA $(M=3.07)$ and control PSA $(M=3.05)$ groups. Post hoc tests show that there was a significant difference $(p<.05)$ between the Omega PSA group and the control PSA group, and a marginally significant difference $(p=.06)$ between the Omega PSA and the state-sponsored PSA group on the measure of awareness of consequences.

The Omega PSA group also scored higher on the measure of perceived harmfulness ( $M=3.79$ on a 5-point scale), as compared to the state- sponsored PSA $(M=3.39)$ and control PSA $(M=3.60)$ conditions. The difference between the Omega and state-sponsored group is statistically significant. Replacing the conflicting message in the statesponsored message (i.e., putting the oil filter in the bathtub) with a clear description of the harmful impact of oil disposal 
in the Omega PSA led to greater recognition for the negative consequences of improper disposal. In addition, since the DTR technique causes participants to pay closer attention to the message, it may have led to more robust encoding of the information and activation of related knowledge.

\section{General Discussion}

In summary, the Omega PSA produced significantly greater intention to properly dispose of used oil filters, as compared to both the state-sponsored and control PSAs, which did not differ from one another. The Omega PSA, utilizing the DTR technique, was highly effective, with more than $50 \%$ of those exposed to the DTR message saying they would take a found oil filter to a collection center. The Omega message was also better than the state- sponsored message at communicating the harmful impact of improper disposal.

These results highlight the benefits of first discerning the underlying obstacles to behavior change, and then employing an empirically validated persuasion technique capable of addressing them (Flay \& Burton, 1990). In this case, our initial field test with DIYers in Study 1 showed that inertia might be creating resistance to the persuasion attempt. We effectively over- came resistance in Study 2 using the DTR technique. This study extends research on the DTR technique by showing that it can also be applied to mass-media communications and not just individual compliance requests. The DTR technique is appealing because we have shown that it does not require face-to-face communication and, therefore, can be incorporated within existing PSAs.

Study 2 has several limitations that should be mentioned. This was a laboratory-based study with college student participants, most of whom (91\%) did not change their own oil. DIYers who have dumped in the past are likely to be more resistant to changing their behavior than our inexperienced college students. However, we believe that these results would generalize to DIYers. In fact, Knowles and Riner (2007) suggested that greater resistance may increase the effectiveness of Omega strategies. 
Another limitation is that the Omega message used in Study 2 differed in a variety of ways from the state-sponsored message, thus making it difficult to pinpoint any one factor that could account for its greater effectiveness. Both the Omega PSA and the state-sponsored PSA included an unexpected element and seemed to capture participants' attention. What the Omega PSA did better was to focus the captured attention on the convenience of proper disposal; a factor that was identified in Study 1 as a perceptual barrier to proper disposal. We attribute the success of the Omega PSA to the combination of uncovering underlying obstacles and using an empirically validated persuasion technique to address them.

Finally, in both studies, our messages were presented to participants in a highly controlled environment, with few distractions. In reality, PSAs are presented to the target audience in a highly media-saturated environment. If the message goes unnoticed, then for all practical purposes, it cannot be expected to influence behavior. Further research is necessary to confirm that the Omega PSA, as it is currently designed, would be effective in a field setting. McGuire (1989) pointed out that there are many basic prerequisites for the success of a PSA campaign. For example, the public must be exposed to the message, understand it, and remember it when there is an opportunity to perform the behavior being promoted. Our focus in this study was on evaluating the influence of the PSA messages once they had been seen. Arguably, if a message cannot influence the listener when it is attended to, then other methods of evaluation - such as how well the message diffused through the target audienceare inconsequential. As with other campaigns that have tried to use knowledge as a motivational tool, the statesponsored PSA campaign, even when it was presented without any other distractions, failed to motivate a behavior change.

The success of the Omega PSA cannot be attributed to participants liking it more or finding it more convincing, as the messages were evaluated as equivalent. Some evaluators conclude that a PSA campaign has been successful if the 
target population evaluates the ad favorably (e.g., Levine \& Zimmerman, 1996). However, the results of the present study indicate that favorable evaluations of a message cannot be used as a basis for deciding that a campaign has been or will be successful in affecting behavior or even behavioral intentions.

Mass-media campaigns can be designed effectively, but they need to address the psychological underpinnings of the behavior and adopt an empirically validated influence technique. Because we were interested in changing, rather than explaining behavior, we did not commit ourselves to any one theoretical starting point. Instead, we measured variables from multiple theories, including the theory of planned behavior (i.e., subjective norms and PBC), Schwartz's (1968) norm activation theory (i.e., ascription of responsibility and awareness of consequences), and Cialdini's (Cialdini, Kallgren, \& Reno, 2000) focus theory (i.e., descriptive and injunctive norms). Results from these measures provide us with an understanding of why the behavior was not occurring: a theory of behavior (Vining \& Ebreo, 2002).

In the case of used motor oil disposal, inaction was the result of inertial resistance and a perception that proper disposal is inconvenient. The theory of change is a theory about what needs to be done in order to effect change. A basic assumption in the psychology of social influence is that persuasion must exceed resistance in order to change behavior (Knowles \& Linn, 2004). In the present study, we used the disrupt-then-reframe technique to overcome inertial resistance and emphasized that proper disposal is convenient.

Campaign designers interested in improving message effectiveness should begin by understanding why the behavior is or is not performed. The first step would be to measure those variables that could potentially impact the behavior, if existing research does not provide this empirical starting point.

Campaign designers could cast a broad net, as we did in Study 1 , or could select a particularly relevant theory.

Once designers have an understanding of the behavior, they can then proceed to designing the PSA message. The PSA message should include those variables identified as important in the model of behavior. For example, if we started with the 
theory of planned behavior (Ajzen, 1991), we would measure attitudes, subjective norms, $\mathrm{PBC}$, and behavioral intentions. If we found that subjective norms were low, we could then initiate a social norms campaign (see Schultz, 2006, for an example of such a campaign). Finally, we believe that all messages can be enhanced by using empirically supported persuasion techniques (see Cialdini, 2001; Knowles \& Linn, 2004; McKenzie-Mohr, 1999).

PSA messages will be more effective when they are empirically derived, rather than being developed from scratch, using intuition and artistry. Cialdini (1989) offered a critique of the Iron Eyes Cody PSA sponsored by the Keep America Beautiful campaign. In closing, he offered two conclusions: "(1) even classic PSAs may contain unintended elements that could undermine optimal effectiveness; and (2) formative research should be con- ducted before expensive PSA production to detect and help eliminate such unfavorable elements." Sadly, now 18 years later, we draw a similar conclusion from our own research on used motor oil disposal: Empirically derived messages are useful, but only when they are used. 


\section{References}

Ajzen, I. (1991). The theory of planned behavior.

Organizational Behavior and Human Decision Processes, $50,179-211$.

Atkin, C. K., \& Freimuth, V. (1989). Formative evaluation research in campaign designs. In R. E. Rice \& C. K. Atkin (Eds.), Public communi- cation campaigns (2 ${ }^{\text {nd }}$ ed., pp. 131-150). Newbury Park, CA: Sage.

Bator, R., \& Cialdini, R. B. (2000). The application of persuasion theory to the development of effective proenvironmental public service announce- ments. Journal of Social Issues, 56, 527-541.

Bratt, C. (1999). The impact of norms and assumed consequences on recy- cling behavior. Environment and Behavior, 31, 630-656.

Brown, S. L. (2001). Emotive health advertising and message resistance.

Australian Psychologist, 36, 193-199.

Browning, R. \& Shafer, H. (2002). DIYers and used oil disposal: Initial results and recommendations (CIWMB Pub. No. 611-01-009). Sacramento, CA: California Integrated Waste Management Board.

California Integrated Waste Management Board. (2002).

California's used oil recycling program (CIWMB Pub. No. 332-97-015). Sacramento, CA: Author.

Chu, P. Y., \& Chiu, J. F. (2003). Factors influencing household waste recy- cling behavior: Test of an integrated model. Journal of Applied Social Psychology, 33, 604-626. Cialdini, R. B. (1989). Littering: When every litter bit hurts. In R. E. Rice \&

C. K. Atkin (Eds.), Public communication campaigns (2nd ed., pp. 221-223). Newbury Park, CA: Sage.

Cialdini, R. B. (2001). Influence: Science and practice (4th ed.). Boston: Allyn \& Bacon.

Cialdini, R. B., Barrett, D. W., Bator, R., Demaine, L. J., Sagarin, B. J., Rhoads, K. L., et al. (2006). Activating and aligning social norms for persuasive impact. Unpublished 
manuscript.

Cialdini, R. B., Kallgren, C. A., \& Reno, R. R. (2000). A focus theory of normative conduct: A theoretical refinement and re-evaluation of the role of norms in human behavior. Personality and Social Psychology Bulletin, 26, 1002-1012. Davis, B. P., \& Knowles E. S. (1999). A disrupt-then-reframe technique of social influence. Journal of Personality and Social Psychology, 76, 192- 199.

Department of Environmental Protection. (2002). How can I save water? Retrieved November 21, 2006, from New York City (www.nyc.gov/html/dep/html/ hcisw.html)

East Boston Online. (1997). "Remake a difference" campaign aims to boost recycling in East Boston as a first step to increasing recycling statewide. Retrieved November 21, 2006, from East Boston

(www.eastboston.com/Moved1226/) recycle2.htm

Ewing, G. (2001). Altruistic, egoistic, and normative effects on curbside recycling. Environment and Behavior, 33, 733764.

Erickson, M. H. (1964). The confusion technique in hypnosis. American Journal of Clinical Hypnosis, 6, 183-207.

Farrelly, M. C., Niederdeppe, J., \& Yarsevich, J. (2003).

Youth tobacco prevention mass media campaigns: Past, present, and future directions. Tobacco Control, 12, 35-47.

Fennis, B. M., Das, E. H. H. J., \& Pruyn, A. T. H. (2004). "If you can't dazzle them with brilliance, baffle them with nonsense": Extending the impact of the disrupt-thenreframe technique of social influence. Journal of Consumer Psychology, 14, 280-290.

Fishbein, M., Hall-Jamieson, K., Zimmer, E., von Haeften, I., \& Nabi, R. (2002). Avoiding the boomerang: Testing the relative effectiveness of anti-drug public service announcements before a national campaign. American Journal of Public Health, 92, 238-245.

Flay, B. R., \& Burton, D. (1990). Effective mass communication strategies for health campaigns. In C. Atkin \& L. Wallace (Eds.), Mass communi- cation and public health: Complexities and conflict (pp. 129-146). Newbury Park, CA: Sage. 
Flora, J. A., Maccoby, N., \& Farquhar, J. W. (1989).

Communication cam- paigns to prevent cardiovascular disease: The Stanford Community studies. In R. E. Rice \& C. K. Atkin (Eds.), Public communication cam-paigns (2nd ed., pp. 7-14). Newbury Park, CA: Sage.

Galst, J. P. (1980). Television food commercials and pronutritional public service announcements as determinants of young children's snack choices. Child Development, 51, 935-938.

Gorn, G. J., \& Goldberg, M. E. (1982). Behavioral evidence of the effects of televised food messages on children. Journal of Consumer Research, 9, 200-205.

Gregory, G. D., \& Di Leo, M. (2003). Repeated behavior and environmental psychology: The role of personal involvement and habit formation in explaining water consumption. Journal of Applied Social Psychology, 33, 1261-1296.

Hopper, J. R., \& McCarl Nielsen, J. (1991). Recycling as altruistic behavior: Normative and behavioral strategies to expand participation in a com- munity recycling program. Environment and Behavior, 23, 195-220.

Irwin, R. J., VanMouwerik, M., Stevens, L., Seese, M. D., \& Basham, W. (1998). Environmental contaminants encyclopedia. National Park Service, Water Resources Division, Fort Collins, CO. Retrieved February 11, 2009 , from

www.fws.gov/caribbean/es/PDF/Contaminants/oilused.pdf. Distributed on the Internet via the Nature Net portion of the Park Service Home Page at National Park Services (www.nps.gov)

Kantola, S. J., Syme, G. J., \& Campbell, N. A. (1984). Cognitive dissonance and energy conservation. Journal of Applied Psychology, 69, 416-421.

Kardes, F. R., Fennis, B. M., Hirt, E. R., Tormala, Z. L., \& Bullington, B. (2007). The moderating role of the need for cognitive closure in the effectiveness of the disrupt-thenreframe influence technique. Journal of Consumer Research, 34, 377-385.

Knowles, E. S., \& Linn, J. A. (2004). Approach-avoidance 
model of persua- sion: Alpha and Omega strategies for change. In E. S. Knowles \& J. A. Linn (Eds.), Resistance and persuasion (pp. 117-148). Mahwah, NJ: Lawrence Erlbaum.

Knowles E. S., \& Riner D. D. (2007). Omega approaches to persuasion: Overcoming resistance. In A. R. Pratkanis (Ed.), Science of social influ- ence (pp. 83-114). New York: Psychology Press.

Laudenslager, M. S., Holt, D. T., \& Lofgren, S. T. (2004). Understanding Air Force members' intentions to participate in pro-environmental behaviors: An application of the theory of planned behavior. Perceptual and Motor Skills, 98, 1162-1170.

Levine, I. S., \& Zimmerman, J. D. (1996). Using qualitative data to inform public policy: Evaluating "Choose to defuse." American Journal of Orthopsychiatry, 66, 363-377. McAlister, A., Ramirez, A. E., Galavotti, C., \& Gallion, K. J. (1989). Anti- smoking campaigns: Progress in the application of social learning theory. In R. E. Rice \& C. K. Atkin (Eds.), Public communication campaigns(2nd ed., pp. 291-307). Newbury Park, CA: Sage.

McGuire, W. J. (1989). Theoretical foundations of campaigns. In R. E. Rice \& C. K. Atkin (Eds.), Public communication campaigns (2nd ed., pp. 43-65). Newbury Park, CA: Sage. McKenzie-Mohr, D. (1999). Fostering sustainable behavior. Gabriola Island, British Columbia, Canada: New Society. Murray, D. M., Prokhorov, A. V., \& Harty, K. C. (1994). Effects of a statewide antismoking campaign on mass media messages and smoking beliefs. Preventative Medicine, 23, 54-60.

Paisley, W. (1989). Public communication campaigns: The American experi- ence. In R. E. Rice \& C. K. Atkin (Eds.), Public communication campaigns (2 ${ }^{\text {nd }}$ ed., pp. 15-38). Newbury Park, CA: Sage.

Prochaska, J. O., \& Prochaska, J. A. (1999). Why don't continents move? Why don't people change? Journal of Psychotherapy Integration, 9, 83-102.

Rice, R. E., \& Atkin, C. K. (1989). Preface. In R. E. Rice \& C. 
K. Atkin (Eds.), Public communication campaigns (2 $2^{\text {nd }}$ ed., pp. 7-14). Newbury Park, CA: Sage.

Schultz, P. W. (2002). Knowledge, information, and household recycling: Examining the knowledge-deficit model of behavior change. In T. Dietz \& P. Stern (Eds.), Education, information, and voluntary measures in environmental protection (pp. 67-82).

Washington, DC: National Academy Press.

Schultz, P. W. (2006). Community-based social marketing pilot to increase do-it-yourself oil recycling rates (CIWMB Pub. No. 611-06-004). Sacramento, CA: California Integrated Waste Management Board.

Schultz, P. W., Nolan, J. M., Cialdini, R. B., Goldstein, N. J., \& Griskevicius,

V. (2007). The constructive, destructive, and reconstructive power of social norms. Psychological Science, 18, 429-433. Schwartz, S. H. (1968). Awareness of consequences and the influence of moral norms on interpersonal behavior.

Sociometry, 31, 355-369.

Stead, M., Tagg, S., MacKintosh, A. M., \& Eadie, D. (2005).

Development and evaluation of a mass media theory of planned behavior intervention to reduce speeding. Health Education Research: Theory and Practice, 20, 36-50. University of Texas-Houston. (2001). Texas tobacco prevention initiative media campaigns and community programs: Effects among children and adults. Houston, TX: University of Texas-Houston, Health Science Center. Vallacher, R. R., \& Wegner, D. M. (1985). A theory of action identification.

Hillsdale, NJ: Lawrence Erlbaum.

Van Liere, K. D., \& Dunlap, R. E. (1978). Moral norms and environmental behavior: An application of Schwartz's norm-activation model to yard burning. Journal of Applied Social Psychology, 8, 174-188.

Vazquez-Duhalt, R. (1989). Environmental impact of used motor oil. Science of the Total Environment, 79, 1-23.

Vining, J., \& Ebreo, A. (2002). Emerging theoretical and methodological perspectives on conservation behavior. In R. B. Bechtel \& A. Churchman (Eds.), Handbook of 
environmental psychology (pp. 541-558). Hoboken, NJ: John Wiley \& Sons.

Whittam, K. P., Dwyer, W. O., Simpson, P. W., \& Leeming, F. C. (2006). Effectiveness of a media campaign to reduce traffic crashes involving young drivers. Journal of Applied Social Psychology, 36, 614-628.

\section{Appendix A}

State-Sponsored Public Service

Announcement Father: What the heck are

you doing, Justin?

Son: Oops, I'm busted.

Father: You just put some crud in my bathwater.

Son: It's just a used oil filter, Dad.

Father: What?

Son: Last week when you changed your motor oil, you threw the used filter in the trash.

Father: Uh huh.

Son: And Uncle Billy told you that the filter was full of oil.

Father: Yeah.

Son: And in the landfill, the oil would sink into the ground and could eventually end up in our water supply.

Father: So, what's your point?

Son: Well, you said that as long as no one saw you do it, it didn't matter. So, I thought if you didn't see me put the oil filter in your bath, it wouldn't matter.

Father: Yea, I'm busted.

Announcer: So what if nobody saw you do it; the oil in a used filter can still hurt the water supply. 
Next time you change your oil and filter, call 1888-CLEAN AR, and we'll give you the location of a collection center near you, at a gas station or auto parts store. Please, do your part because the reality is $50 \%$ of oil sold is never collected.

Copyright $\mathbb{C} 2002$ by the California Integrated Waste Management Board.

Reprinted with permission of the CIWMB Office of Public Affairs.

\section{Appendix B}

Omega Public Service Announcement

Announcer: Used motor oil contains heavy metals like lead, and heavy polycyclic aromatic hydrocarbons that are thought to be carcinogenic. And it's not just the oil itself; even used oil filters can be harmful! Used oil filters are full of oil. If filters are put in the trash, they end up in the landfill where the oil will sink into the ground and could eventually end up in our water supply. Even if no one knows the filter is in the trash, the oil in a used filter can leak out and hurt the water supply. Please, do your part. Next time you change your oil and filter, call 1-888-CLEAN AR, and we'll give you the location of a collection center near you, at a gas station or auto parts store. Typically, there will be a collection center in less than 47,520 inches from your home - that's $3 / 4$ of a mile. It's convenient! 


\section{Appendix C}

\section{Control Public Service}

Announcement Father: What the heck are

you doing, Justin?

Son: Oops, I'm busted.

Father: You just put some crud in my bathwater.

Son: It's just some ink, Dad.

Father: What?

Son: Last week when you bought your new pen, you threw the old one on the ground.

Father: Uh huh.

Son: And Uncle Billy told you not to litter.

Father: Yeah.

Son: That litter could have ruined someone's day!

Father: So, what's your point?

Son: Well, you said that as long as no one saw you do it, it didn't matter. So, I thought if you didn't see me put the ink in your bath, it wouldn't matter.

Father: Yea, I'm busted.

Announcer: So what if nobody saw you do it; littering hurts the environment. Next time you see someone litter, call 1-888- CLEAN AR. Please, do your part, because the reality is we can't keep the streets clean without your help! 